\title{
OS PRINCÍPIOS DE JUSTIÇA DE RAWLS E AS CRÍTICAS À TEORIA DE JUSTIÇA
}

Barbara das Neves

Mestranda em Direito do Estado da Universidade Federal do Paraná. Especialista em Direito Tributário pelo Instituto Brasileiro de Estudos Tributários (IBET). Graduada em Direito pelo Centro Universitário Curitiba (UNICURITIBA) e em Ciências Contábeis pela Universidade Federal do Paraná. Professora e Advogada. Email: barbaradasneves@gmail.com

Mauricio Wosniaki Serenato

Mestrando em Direito do Estado pela Universidade Federal do Paraná. Bacharel em Direito pela Universidade Federal do Paraná. Membro do Núcleo de Pesquisa "Constitucionalismo e Democracia: filosofia e dogmática constitucional contemporânea", vinculado ao Programa de Pós-Graduação em Direito da UFPR. Atualmente é advogado.

\section{RESUMO}

O presente artigo tem por objetivo investigar a teoria política e moral de John Rawls, matizando-a com críticas a partir de diferentes concepções filosóficas e teóricas, de modo a trazer novas perspectivas à obra do autor. Para tanto, estudase o pensamento rawlsiano em suas principais características e categorias, tal como a ideia de posição originária, contrato social, justiça como equidade e princípio da diferença. A partir desse escopo teórico trazem-se as críticas protagonizadas por Michael Sandel, na vertente comunitarista, Robert Nozicki, na vertente libertária, e Enrique Dusse, na vertente da Filosofia da Libertação. Pretende-se, desse modo, analisar os limites e possibilidades da obra de John Rawls tomando por base problematizações que, apesar de bastante distintas, qualificam o debate teórico.

PALAVRAS-CHAVE: Teoria da Justiça. John Rawls. Michael Sandel. Robert Nozicki, Enrique Dussel.

\section{THE JUSTICE PRINCIPLES OF JOHN RAWLS AND THE CRITICS OF JUSTICE THEORY}




\begin{abstract}
The objective of the following article is to investigate the main ideas of political and moral theory proposed by John Rawls, related to original position, social contract, justice as equity and the principle of difference. These ideas will be introduced before the critics of his perspective by Michael Sandel, Robert Nozicki and Enrique Dussel. Finally, the article endeavors in the analysis of the limits and application of John Rawl's work.
\end{abstract}

KEYWORDS: Justice Theory. John Rawls. Michael Sandel. Robert Nozicki. Enrique Dussel.

\title{
1 INTRODUÇÃO
}

A teoria política e moral elaborada por John Rawls se apresenta como uma das mais influentes e debatidas da contemporaneidade. Com efeito, sua teoria da justiça, da qual decorrem ideias como a posição originária e princípio da diferença, consubstancia tema de reflexão para pensadores de diversas vertentes filosóficas e políticas da atualidade.

Ainda que filiado a uma postura liberal, John Rawls avança em uma série de temas e aprofunda a visão contratualista a partir de um paradigma verdadeiramente neocontratualista, que vê o "Contrato Social" não como o ato de limitação do Estado de Natureza, mas sim como a definição dos valores e princípios morais escolhidos pelos indivíduos na posição originária.

De toda sorte, e como justificativa de sua alocação teórica dentro de uma perspectiva liberal, Rawls é um defensor do individualismo e da liberdade formal, ainda que matizada materialmente por suas ideias tais como o princípio da diferença.

Sem embargo da inequívoca importância do pensamento rawlsiano, há uma série de críticas às concepções do autor, que perpassam desde suas concepções morais, até mesmo políticas, produzidas por autores de ambos os lados do espectro ideológico.

O que se pretende com o presente trabalho, portanto, é, de modo objetivo e sem pretensão de esgotar todos os meandros do tema, analisar a proposta teórica de John Rawls em suas principais categorias para, na sequência, apresentar algumas críticas de distintos aspectos a teoria rawlsiana.

Para tanto, de início se analisará o cerne da teoria de John Rawls em seus principais aspectos. Na sequência se apresentará a crítica comunitarista à Rawls, mormente a partir das teorizações de Michael Sandel acerca da concepção de sujeito. Igualmente, observar-se-á a crítica libertária produzida por Robert Nozicki, precipuamente no que tange ao princípio da diferença. Por fim, será estudada a perspectiva de Enrique Dussel, em sua crítica ao formalismo 
neocontratulista rawlsiano e à pretensão universalizante de Rawls.

Ao fim e ao cabo, trata-se de qualificar a teoria de Rawls a partir de críticas que não olvidam da relevância rawlsiana, mas trazem pertinentes apontamentos, a partir de suas próprias perspectivas, indicando para um horizonte teórico que é, ao mesmo tempo, repleto de limites e possibilidades.

\section{OS PRINCÍPIOS DE JUSTIÇA DE RAWLS}

John Rawls, filósofo norte-americano de visão neocontratualista, ficou conhecido por sustentar uma abordagem da justiça a partir da ideia de equidade, sob uma vertente político filosófica do pensamento liberal em sua obra "A Teoria da Justiça", e demais publicações que consistiram em esclarecimentos sobre seu posicionamento original.

Seu pensamento é derivado fundamentalmente de um modelo renovado de Estado do século XX, com a propositura de um acordo baseado em princípios de justiça, em oposição ao utilitarismo e intuicionismo (RAWLS, 2000, p. 12). ${ }^{1}$

Quanto ao utilitarismo, Rawls argumenta que a perspectiva igualitária original da teoria acabou frustrada, na medida em que a ideia de bem independe da noção de justiça desde que satisfaça a maioria dos membros de determinada sociedade. Ou seja, uma determinada prática será aceita desde que as instituições atinjam o maior saldo líquido de satisfação dos indivíduos, não sendo analisadas, por exemplo, a distribuição desta satisfação e a duração desta ideia inicial de felicidade.

Por esta razão, Rawls acredita que em uma situação inicial (contrato social) os indivíduos não optariam pelo utilitarismo, afinal de contas seria possível que estas mesmas pessoas fizessem parte de uma minoria oprimida, caso esta circunstância estivesse de acordo com a maioria (RAWLS, 2000. p. 29).

Rawls parte da ideia de liberdades básicas inerentes aos indivíduos, pressupondo que cidadãos sejam livres. Segundo sua concepção de justiça, há de se garantir a plena liberdade de cada indivíduo, de forma igualitária, para poder escolher e buscar uma vida adequada, tendo por limite o respeito aos demais indivíduos. Conclui que "numa sociedade justa as liberdades básicas são tomadas como pressupostos e os direitos assegurados pela justiça não estão sujeitos à negociação política ou ao cálculo dos interesses sociais” (RAWLS, 2000. p. 31).

\footnotetext{
${ }^{1}$ Rawls também é autor do Liberalismo Político, de 1993. O direito dos Povos, em 1999. História da Filosofia Moral, de 2000. Justiça como Equidade - uma reformulação, em 2001.

Complexitas - Rev. Fil. Tem., Belém, v. 3, n. 2 , p. 66-84, jul./dec. 2018 - ISSN: 2525-4154
} 
Rawls, diferentemente do contratualismo clássico, em vez de enfatizar a compreensão do contrato social como mecanismo de superação das dificuldades do estado de natureza, focou o acordo como forma de se justificar racionalmente princípios que permitam alcançar a justiça e a igualdade (equidade). Ou seja, ao contrário da concepção utilitarista, o critério de justiça é anterior à noção do próprio bem, de modo que não se podem atribuir violações de direitos individuais e liberdades apenas como justificação do encontro da felicidade como legitimação da atividade estatal.

Nas palavras de Sandel, Rawls "argumenta que a maneira pela qual podemos entender justiça é perguntando a nós mesmos com quais princípios concordaríamos em uma situação de equidade" (SANDEL, 2011. p. 177).

Ocorre que seria muito difícil chegar a um consenso, tendo em vista que pessoas diferentes teriam princípios diferentes em razão de interesses diversos, tais como crenças morais, religiosas e política. A sociedade, neste caso, seria uma associação de acordo entre indivíduos, sendo o Estado a garantia deste contrato, de modo a assegurar a existência equitativa de interesses privados.

O objetivo de Rawls é demonstrar como a justiça é realizada nas estruturas bases da sociedade e, para validar sua teoria, o autor vai sugerir o retorno da análise do Pacto Original, ou seja, em uma situação hipotética de igualdade entre todos os indivíduos.

Neste primeiro momento, todos os indivíduos estariam nivelados em termos de conhecimento, direitos, obrigações, para somente depois encontrar uma situação justa e conveniente de convivência social entre as pessoas (igualdade social). Seria o que o autor denomina de "véu de ignorância", no qual temporariamente os indivíduos se esqueceriam de quem realmente são. Não teriam consciência de raça, crença, classe social, gênero, sorte, inteligência, força, raça, dentre outras características (RAWLS, 2000, p. 152).

Também não conhecem concepções de bem e psicológicas, de modo que ficaria “excluído o conhecimento destas contingências que criam disparidades entre os homens e permitem que eles se orientem pelos seus preconceitos" (RAWLS, 2000, p. 21).

No entanto, este véu da ignorância não seria absoluto, na medida em que as partes conheceriam "as relações políticas e os princípios da teoria econômica; conhecem a base da organização social e as leis que regem a psicologia humana” (RAWLS, 2000, p. 148). Também não impediria o conhecimento de descobertas básicas para ciências sociais, em matéria de economia e psicologia social. Ou seja, os sujeitos desconhecem qualquer informação que possa 
ser utilizada em favor de si mesmos, de modo que podem chegar a uma conclusão imparcial.

Daí advém a ideia de Rawls de equidade para fundamentar os princípios da justiça. Ou seja, se os indivíduos desconhecem todos estes fatores, na visão do autor seria possível fazer uma escolha a partir de uma posição original de equidade. Como não existiria nenhuma posição superior entre os indivíduos, os princípios identificados para este acordo inicial (contrato social) seriam considerados justos, já que os indivíduos não defenderiam interesses próprios, grandes dificuldades atreladas às teorias do contratualismo.

O autor não imagina a justiça como esfera individual de cada indivíduo, mas como algo que parte das instituições, de forma a beneficiar ou prejudicar a comunidade vinculada. Este contrato original procura estabelecer princípios básicos de justiça. Tais princípios não seriam propostos para resolver problemas gerais do cotidiano, mas como critérios aplicáveis à estrutura básica da sociedade.

Ou seja, como as instituições mais importantes, para ele as constituições políticas, econômicas e sociais, distribuem direitos e deveres fundamentais. Ainda, os princípios foram imaginados para uma sociedade organizada, que promova o bem para a sociedade, sem uma profunda escassez ou abundância. Nesta sociedade as pessoas seriam iguais entre si e também vulneráveis às agressões dos demais.

Pelas condições procedimentais imparciais, estas levam, segundo Rawls, ao que ele denomina de justiça como equidade. Princípios que seriam eleitos por pessoas livres, racionais e interessadas em si mesmas (não invejosas), e colocadas em condição de igualdade.

Rawls imagina uma situação em que a discussão ocorra por indivíduos racionais e interessados, que se propõem a eleger, por unanimidade, e depois deliberar entre eles, os princípios sociais que irão organizar a sociedade.

Neste sentido, é possível afirmar, inclusive, que sua teoria se aproxima de uma noção de uma moral universalista e do imperativo categórico de Kant, na medida em que ao recorrer à posição original e ao véu da ignorância estariam os indivíduos sujeitos a uma postura universal.

Analisa-se, portanto, mais o interesse de todas as partes vinculadas a este acordo inicial do que cada indivíduo específico. Neste acordo inicial os indivíduos teriam a desculpa da "ignorância", ou seja, um desconhecimento inicial da justiça, em que seria possível optar por direitos e deveres a serem conquistados neste primeiro momento.

Porém, Rawls indica que este desconhecimento não seria suficiente. Seria necessário ainda estabelecer quais os propósitos originais deste acordo e qual seria o critério de desempate, 
na hipótese de incertezas sobre as decisões originárias. O autor então argumenta que as motivações iniciais destes indivíduos seriam os bens primários (sociais, como oportunidades de direitos, e naturais, como talentos e saúde), necessários independentemente do padrão de vida dos participantes. Além disso, as incertezas seriam sempre solucionadas de acordo com uma hierarquia sobre qual seriam as piores hipóteses em discussão (nenhum indivíduo escolheria a escravidão se não pudesse ter a certeza de que esta não seria sua realidade).

Para que as instituições se organizem de modo a alcançar justiça proposta, Rawls discorre sobre quais seriam os princípios que seriam eleitos com base nesta ignorância inicial, livres de convicções pessoais.

Conclui o autor que não seriam escolhas baseadas no utilitarismo, nem mesmo no princípio libertário total, pois existiria o receio de tais indivíduos estarem em condições de minoria. Em sua opinião, como forma de proteção desses perigos, existiria um acordo sobre liberdades básicas iguais para todos os cidadãos e não existiriam sacrifícios de liberdades fundamentais para benefícios sociais e econômicos. Afinal de contas, já que desconhecem a condição social inicial, concluiu-se que as primeiras preocupações consistiriam em garantir o mínimo necessário à convivência em sociedade.

Esta distribuição de direitos e deveres, na visão de Rawls, concederia mais benefícios do que as pessoas conseguiriam com uma liberdade ilimitada. Em outras palavras, na sua visão a sociedade liberal não estaria ligada pelas considerações relativas ao interesse particular de cada um, mas pelas considerações morais partilhadas relativamente à liberdade igualitária de todos.

Neste caso, Rawls acredita que seriam dois os princípios que surgiriam deste contrato hipotético na posição inicial: (i) o principio de que cada pessoa deve ter igual direito ao mais abrangente sistema de liberdades básicas que seja compatível com o sistema de liberdades para outros indivíduos. Ou seja, sejam quais forem as decisões tomadas pelas instituições, a ideia é que não prejudiquem ou discriminem os sujeitos neste pacto original; e o (ii) princípio pautado em uma equidade social e econômica, permitindo desigualdades apenas em benefício aos menos favorecidos em uma sociedade.

Quanto ao primeiro princípio, fica clara a posição de Rawls no sentido de que sua teoria não admite benefícios por circunstâncias alheias às escolhas dos agentes (por exemplo, nascer em uma família rica). Ou seja, neste caso os sujeitos não fariam nada para merecer tais benefícios.

Nesta circunstância, todas as pessoas deveriam possuir um sistema de direitos e 
liberdades iguais para todos, sendo este programa compatível com os direitos e liberdades de outros indivíduos. No entanto, existiriam certos direitos e liberdades que deveriam ser privilegiados em detrimento de outros existentes em sociedade. Em síntese, os direitos que emanam do primeiro princípio de justiça seriam:

[...] a liberdade política (o direito de votar e ocupar um cargo público) e a liberdade de expressão e reunião; a liberdade de consciência e de pensamento; as liberdades da pessoa, que incluem a proteção contra a opressão psicológica e a agressão física (integridade da pessoa); o direito à propriedade pessoal e a proteção contra prisão e a detenção arbitrárias, e acordo com o conceito de estado de direito (RAWLS, 2000, p. 65).

Em outras palavras, os direitos decorrentes do primeiro princípio de justiça se destinam fundamentalmente a garantir uma esfera de inviolabilidade de direitos básicos para sustentar a estrutura básica de justiça, ou seja, vinculados à esfera privada dos cidadãos. Rawls procura fundamentar o princípio de igual liberdade em um mínimo razoável de direitos para todos os indivíduos de modo a controlar a equidade inicial e igualdade de perspectiva entre as partes.

Quanto ao segundo princípio, o autor defende que a situação de tratamento desigual para pessoas desiguais resultaria em um equilíbrio social, que beneficiaria a própria sociedade, na medida em que todos teriam igualdade de oportunidades. Ou seja, com a equidade social e econômica permite-se "apenas desigualdades sociais e econômicas que beneficiem os membros menos favorecidos de uma sociedade" (SANDEL, 2011. p. 179).

O segundo princípio, chamado "da diferença", pressupõe que as desigualdades sociais e econômicas deverão ser aplicadas de modo que sejam vantajosas para todos. Trata-se de princípio que discorre sobre a distribuição de recursos na sociedade, ou seja, superação da ideia de justiça distributiva. Não há, na percepção de Rawls, uma mera ideia de igualdade de oportunidades, na medida em que eventuais vantagens só são aceitas se agregarem algum benefício aos demais.

Pela percepção do autor, a simples largada dos indivíduos em uma posição inicial igualitária não seria suficiente, na medida em que seria possível prever quem seriam os vencedores, ainda que sob uma perspectiva da meritocracia. Afinal de contas, ainda que com oportunidades iguais pelo mercado, a loteria natural faria com que determinados indivíduos fossem beneficiados em detrimento de outros.

Até mesmo a teoria do esforço é rechaçada por Rawls, na medida em que esta virtude estaria, na opinião do autor, atrelada aos favorecimentos familiares e facilidades sociais. Seriam 
créditos que os indivíduos não poderiam reivindicar para si, nem mesmo sob o argumento do merecimento.

Sandel cita o exemplo da hipótese de médicos bem remunerados relacionados ao segundo princípio de Rawls. Neste caso, salários mais altos para médicos só seriam permitidos caso esta diferença proporcionasse melhores condições de atendimentos médico em regiões de baixa renda (SANDEL, 2011. p. 189). Ou seja, a ideia não seria avaliar se os salários altos são justos ou não, mas sim se esta concentração de fortuna faz parte de um sistema que trabalha em prol dos menos favorecidos.

A questão principal é a de que não há pretensão de inibir aptidões e impor limitações de talentos, mas indicar que recompensas por estas vantagens pertençam à comunidade em geral. Ou seja, o autor não quer sugerir, por exemplo, que os talentos naturais sejam excluídos de determinada sociedade, pois isso seria inviável, mas procura justificar que a forma como as instituições processam este fator é que deveriam ser alteradas, sempre prezando pela justiça (a virtude inicial das instituições em sua opinião).

Como explica Gargarella, “a ideia é que cada um deve aceitar o preço das escolhas para as quais tende: no ideal da concepção liberal, os indivíduos devem ser considerados responsáveis sobre suas próprias ações, e não meras vítimas de seu destino" (GARGARELLA, 2008. p. 27).

Em outras palavras, se os incentivos aos mais ricos, por exemplo, gerassem crescimento econômico ao ponto de beneficiar os desafortunados a terem uma vida melhor, então o Princípio da Diferença estaria sendo respeitado. Não seria um direito moral daqueles que possuem alguma aptidão natural ou possuam melhores condições financeiras, mas sim uma circunstância aceitável em virtude dos benefícios aos menos privilegiados.

Em suma, a proposta do autor parte da ideia de que a justiça distributiva não estaria vinculada a noção de recompensação por méritos morais, mas sim pelo atendimento legítimo as condições específicas acordadas pelos participantes após o acordo inicial e os princípios ali estabelecidos. Caso os indivíduos atendessem estes padrões, então seriam merecedores pelo cumprimento das regras e não poderiam reclamar das condições pré-estabelecidas (por exemplo, a tributação superior em detrimento da riqueza auferida).

Em outras palavras, o que se define neste acordo inicial é a estrutura fundamental da sociedade, ou seja, os objetivos que sustentam a convivência social daquele instante inicial em diante. Trata-se de um critério objetivo e racional, na medida em que todos estariam vinculados 
ao modelo sabendo dos benefícios e obrigações que se sujeitariam no futuro.

Ao ser conquistado este objetivo, as realizações pessoais seriam possíveis, de forma em resultar melhores condições para cada individuo, porém, com o respeito às condições gerais do acordo inicial celebrado.

Deste modo, o modelo apresentado por Rawls é baseado em dois princípios fundamentais: o da garantia de liberdade e o da distribuição igual para todos. Na opinião do autor, se estes dois princípios forem realmente aplicados, haverá estabilidade social.

Os críticos de sua teoria questionam se seriam estes os dois princípios eleitos em uma situação hipotética de ignorância. Além disso, indicam que um contrato não garantiria, necessariamente, equidade, e que o consentimento não seria suficiente para criar uma obrigação moral. Os indivíduos com mais talento e aptidão poderiam simplesmente optar por não desenvolver tais vantagens em razão do princípio da diferença proposto por Rawls.

As críticas, neste caso, existiriam exatamente sobre a oposição de um acordo hipotético que, em tese, não teria aplicabilidade atual, pois esta condição de igualdade já não existiria. Inclusive, a quantidade de críticos a sua obra já diz muito sobre a contemporaneidade e importância de suas opiniões para a filosofia política. Para tanto, e como tentativa de demonstrar a interdisciplinaridade de sua teoria, passaremos a seguir a demonstrar as considerações realizadas por Michael Sandel (associado ao comunitarismo), Robert Nozicki (sob uma perspectiva do liberalismo conservador) e Enrique Dussel (com a proposta de uma filosofia da libertação).

\section{O MICHAEL SANDEL E O COMUNITARISMO CONTEMPORÂNEO}

Sandel desponta como um dos principais autores contemporâneos do comunitarismo e, por tal razão, apresenta algumas críticas à posição contratualista e, de certa forma, individualista de John Ralws.

Apesar de argumentar que a posição de Rawls não decorre de uma objeção direta às aptidões naturais, mas sim a uma justiça na distribuição dos benefícios a partir destas vantagens, a crítica de Sandel parte, sobretudo, do conceito de sujeito (indivíduo) em Rawls e se espalha para outras concepções do autor, como a ideia de princípio da diferença e da posição originária dos sujeitos da sociedade. Para tanto, é importante iniciar com a concepção de sujeito em Rawls.

Para Rawls o pressuposto da tomada do indivíduo como sujeito é ser livre e igual para 
desse modo participar de uma cooperação social equitativa. Assim, o indivíduo será livre e igual quando for capaz de possuir e reconhecer que outros possuem a faculdade moral de ter uma concepção de bem. Igualmente, é preciso que o indivíduo se reconheça como fonte de reivindicação que possa promover a sua visão de bem (MULHALL; SWIFT, 1996, p. 50). O indivíduo em Rawls é um agente capaz de decidir a respeito de sua concepção de bem, de buscar concretizá-la e assumir a responsabilidade pelos encargos daí decorrentes.

Veja-se, portanto, que na constituição do sujeito em Rawls, é mais importante o poder de escolha de uma concepção de bem do que esta escolha em si. Dessa forma, não é a visão de bem que eu escolho que me torna sujeito, mas sim o fato de eu poder fazer essa escolha. Sandel já faz uma primeira crítica a essa concepção rawlsiana, alegando se tratar de uma ideia metafísica do sujeito, que não é confirmado a partir de suas escolhas, mas sim do fato anterior de poder escolher (MULHALL; SWIFT, 1996, p. 41). Sandel vai além e tece mais três críticas.

A concepção de pessoa em Rawls seria tão somente voluntarista, ou seja, a concepção de bem e os fins adotados pelo sujeito decorrem de sua mera escolha, excluindo-se daí a ideia de que as concepções de bem adotadas pelo sujeito se dão muitas vezes mais por um ato de reconhecimento do que de escolha racional.

Nesse aspecto, é de se observar como essa concepção metafísica de Rawls acaba por servir aos propósitos justificadores do liberalismo. Conforme aponta Sandel, a prioridade do sujeito sobre a comunidade, isto é, a ideia de que a comunidade é prescindível para a definição de valores morais próprios dá evidente ênfase a um individualismo que é a base do liberalismo (SANDEL, 1998, p. 21).

Além disso, considerando que a identidade do sujeito é fixada anteriormente a escolha de uma concepção de bem, haverá sempre uma distância entre o sujeito e sua concepção de bem. Assim, tal concepção acaba sendo um interesse do indivíduo, como algo a ser possuído e não constitutivo de sua própria identidade.

Por fim, e sob uma perspectiva do olhar comunitarista, Sandel indica que o senso de comunidade em Rawls seria bastante raso, sendo descrito como um possível objetivo de sujeitos anteriores individualizados. Isto é, a relação com a comunidade não integraria a identidade do sujeito.

As críticas tecidas por Sandel à ideia de sujeito de Rawls desembocam também na crítica que ele traça ao princípio da diferença e a ideia da posição originária.

Como já visto, para Rawls a distribuição de dons e talentos naturais, assim como da 
posição social, é algo inteiramente contingente e aleatório do ponto de vista moral, não havendo qualquer mérito do sujeito em possuí-los e, justamente por isso, fica excluída a possibilidade de um usufruto estritamente individual desses "ativos". Mais do que isso, o indivíduo não merece os frutos de seus dons e talentos porque, na concepção de pessoa de Rawls, tal como abordado por Sandel, esses atributos não são constitutivos do sujeito (MULHALL; SWIFT, 1996, p. 62).

Sandel identifica algumas contradições no pensamento rawlsiano, como o fato de não haver mérito individual na posse de dons naturais e, portanto, o indivíduo não poder usufruir desses dons de modo individual não justificaria automaticamente a conclusão de que a sociedade teria esse mérito e poderia usufruir desses dons (MULHALL; SWIFT, 1996, p. 62). Assim, de onde viria esse direito que caberia a sociedade?

Para Sandel, Rawls só poderia responder essa pergunta se admitisse que algumas vezes o sujeito é identificado com os membros de sua comunidade em um sentido constitutivo, de modo que a redistribuição dos frutos e talentos de um indivíduo em si não implicaria sua utilização como um meio, mas efetivamente como um fim. Assim, o senso de comunidade seria forte o suficiente para transcender uma postura eminentemente individualista do sujeito. Assim, para Sandel, a justificação do princípio rawlsiano da diferença somente seria possível a partir de uma concepção intersubjetiva do "eu" e de uma concepção constitutiva da comunidade (MULHALL; SWIFT, 1996, p. 63).

Quanto à posição originária, ou seja, a situação inicial hipotética em que os sujeitos, cobertos pelo véu da ignorância, decidem sobre quais princípios irão reger a sociedade e as instituições, Sandel argumenta que a ideia proposta por Rawls acaba por afastar todas as diferenças entre as partes que confirmam o contrato social.

De fato, o véu da ignorância tem o condão de extirpar as diferenças sociais e naturais dos indivíduos de modo que a escolha dos princípios de justiça ocorra de modo equitativo e não pautada por interesses decorrentes da posição de cada qual. Dessa forma, conforme argumenta Sandel, não há um verdadeiro acordo entre os sujeitos, uma vez que não existem distinções entre os participantes. $\mathrm{O}$ acordo não seria uma livre pactuação feita entre as partes, mas o reconhecimento da validade de algumas proposições, uma concordância cognitiva, de modo que por trás do véu da ignorância não haveria várias pessoas, mas um único sujeito. Para Sandel isso demonstra que Rawls acaba por atribuir um forte senso de comunidade como requisito para a aceitação da posição original (SANDEL, 1998, p. 132).

Em suma, Sandel demonstra que tanto a concepção de posição original quanto a ideia do 
princípio da diferença demandam, ao fim e ao cabo, um sentido constitutivo de comunidade e que, portanto, não poderiam se adequar à concepção de sujeito defendida por Rawls.

De certa, acaba retirando algumas características comunitárias da Teoria da Justiça por Rawls, afirmando, por fim, que "quer sua teoria [a de Rawls] de justiça venha a ser aceita, quer não, ela representa a proposta mais convincente de uma sociedade equânime já produzida pela filosofia política americana" (SANDEL, 1998, p. 204).

\section{ROBERT NOZICK E O LIBERALISMO CONSERVADOR}

Robert Nozicki é um dos mais importantes marcos teóricos libertários, servindo de fundamentação teórica para as mais radicais vertentes do liberalismo econômico. Foi colega de Harvard de Rawls e, em seu principal trabalho, Anarquia, Estado e Utopia, traz uma contundente crítica à Rawls, sobretudo no que diz respeito ao princípio da diferença preconizado pelo autor, defendo que sua opinião seria insuficientemente liberal.

Ao contrário do liberalismo igualitário de Rawls que, conforme visto, pretendia argumentar que a justiça social a partir de uma atuação significado do Estado, Nozick defende um Estado mínimo, essencialmente com a função de proteger os indivíduos contra roubos, fraudes, força ilegítima (em oposição ao Estado de natureza) e amparar o cumprimento de contratos.

Neste caso, argumenta que é possível obter um Estado mínimo sem a violação de direitos (vida, liberdade e propriedade) e que é moralmente necessário um Estado mínimo, em comparação a inexistência desta instituição.

Tal como Rawls, defende direitos mínimos que não podem ser desrespeitados, nem mesmo em favor de outros indivíduos ou sob o argumento de uma causa maior (utilitarismo). Cada indivíduo seria proprietário de sua vida, tendo condições necessárias para levar sua vida adiante. Estes direitos seriam negativos (de não interferência quando comparados com outros indivíduos), sendo que os positivos seriam apenas os que resultam de acordos voluntários.

Contudo, a função mínima do Estado, neste caso, seria garantir a não interferência nos direitos mínimos dos indivíduos, mas não garantir valores positivos que facilitem a vida destas pessoas. Trata-se da principal distinção entre as duas teorias.

A segunda diferença consiste na ideia de autopropriedade. No posicionamento defendido pelo liberalismo igualitário de Rawls, seria justo que os mais talentosos colocassem estes talentos em favor dos que possuem menos aptidões. Para Nozick, no entanto, isto seria uma 
nova forma de escravidão, em prol de um ideal de justiça. A proposta de Rawls seria exatamente o que o liberalismo conservador procura evitar: que o esforço de alguns indivíduos seja uma garantia à subsistência dos demais. Nozick se recusa a aceitar que em uma sociedade livre, indivíduos optariam pela redistribuição.

Nozick questiona a ideia de Rawls de que os indivíduos, na posição original, realmente optariam pelo princípio da diferença proposto por Rawls, na medida em que esta ideia partiria de uma noção de grupo e não dos próprios indivíduos em questão. Não estaria claro que "grupos são corretamente considerados. Por que excluir o grupo de deprimidos, alcoólatras ou paraplégicos representativos?” (NOZICK, 2003. p. 209).

A ideia do Estado mínimo de Nozick é que os sujeitos iriam preferir reunir-se em grupos, para proteção mútua. Até se chegar a uma única instituição no topo, que seria o Estado mínimo, em que estes indivíduos seriam persuadidos pela ideia de proteção ou obrigados moralmente. Ou seja, seria a proteção conveniente que faria com que a organização ocorresse.

Quanto à ideia igualitária, Nozick não é contra, mas não admite que isso seja uma imposição, na medida em que isso seria moralmente contestável e um esforço em vão. A uma, em razão de que as pessoas são naturalmente diferentes. A duas, ao menos que se restrinja a liberdade de cada um ser diferente do outro ou de uma intrusiva interferência do Estado, o posicionamento igualitário não seria praticável.

O autor exemplifica esta ideia com o caso do jogador de basquete Wilt Chamberlain. Neste caso, existiria uma sociedade totalmente igualitária, com igual distribuição de rendimentos (segundo o princípio da diferença D1). Porém, nesta sociedade vive o jogador de basquete Chamberlain, que é o grande jogador do momento e decide assinar o seguinte contrato com uma equipe: nos jogos em casa, receberá vinte e cinco centavos a cada ingresso vendido. Os espectadores aceitam este acordo e ainda pagariam mais apenas para ver o jogador em campo.

Como Wilt é a grande sensação do basquetebol do momento, todos o querem ver jogar de modo que ao final da temporada 1 milhão de pessoas assistiram aos jogos e Chamberlian recebeu 250.000 mil dólares.

Porém, no final dos jogos, o atleta possui muito mais dinheiro que os companheiros, gerando-se uma nova distribuição de riqueza (D2). Nozick se pergunta o que existiria de injusto nesta situação, afinal de contas todos estavam em situação de igualdade e aceitaram aquela situação. 
Na situação D1, as pessoas tinham um rendimento legítimo e não havia protestos de terceiros para que se redistribuísse a riqueza. Depois as pessoas escolheram dar vinte e cinto centavos do seu rendimento a Chamberlain e gerou-se a distribuição D2. Haverá agora lugar a reclamações de terceiros que antes nada reclamavam e que continuam a ter o mesmo rendimento? Que razão há para se redistribuir a riqueza? Que razão tem o Estado para interferir no rendimento de Chamberlain cobrando-lhe impostos elevados?

O que Nozicki pretende dizer com este exemplo é o seguinte: o princípio da diferença de Rawls é uma concepção padronizada de justiça, que determina que os bens devem ser distribuídos de modo que os mais desfavorecidos fiquem da melhor maneira possível. No entanto, as pessoas podem ter diferentes atitudes quanto a esses bens recebidos. Podem tanto gastá-los quanto guardá-los e procurar receber mais. Assim, essas ações livres dos indivíduos conseguem quebrar o padrão da distribuição segundo o princípio da diferença. Para que o padrão seja recomposto o Estado teria de intervir, sobretudo a partir da cobrança de impostos. Assim, o Estado tiraria bens legitimamente possuídos por indivíduos sem o seu consentimento para favorecer os mais desfavorecidos.

De acordo com Nozicki, esta redistribuição interferiria na liberdade e nos direitos de propriedade, por ele considerados absolutos. Tal interferência seria, portanto, eticamente inaceitável.

Essa concepção de Nozicki parte da crença que a retirada de bens dos mais favorecidos em prol dos menos favorecidos afrontariam a dignidade dos primeiros, na medida em que estariam sendo usados como meios ainda que o objetivo seja o bem da maioria.

Gargarella (GARGARELLA, 2008, p. 487) explica que talvez Nozick leve vantagem nesta discussão pela "transação voluntária". Ou seja, não há nenhuma imposição, de modo que as pessoas estariam agindo por vontade própria e não poderiam ser recriminadas.

Em outras palavras, seria recriminável um trabalhador assinar um contrato sob a mira de um revólver, porém, não teria nada de errado em aceitar um contrato desfavorável apenas em razão de necessitar o trabalho. O trabalhador é o responsável pelos acordos que aceitar.

No entanto, Gargarella ressalta que não seria este o propósito do depósito do valor adicional no exemplo do jogador de basquete, na medida em que talvez, caso fossem questionados sobre distribuição não igualitária, a resposta fosse diferente. Ou seja, a transação seria aceita se os indivíduos soubessem o real propósito?

Quanto ao direito de propriedade, Nozick fundamenta sua opinião baseado em Hayeck, 
na medida em que a transferência de propriedade seria um benefício para sociedade, por estar servindo a um propósito. A propriedade seria adquirida caso a justiça na transferência inicial ou aquisição tivesse sido justa.

$\mathrm{Na}$ tentativa de defender sua posição, Nozick utilizou o recurso do princípio de retificação. $\mathrm{O}$ autor esclarece que algumas transferências ou apropriações podem ter ocorrido de maneira equivocada e, por isso, precisam de retificação. Ou seja, seria um princípio que buscaria apagar eventuais injustiças. Porém, a completa organização social poderia ser posta de cabeça para baixo.

Assim, o próprio Nozick parece admitir práticas redistributivas, por reconhecer que o princípio de retificação seria impraticável após a estrutura injusta atual da sociedade. A redistribuição ocorreria para reparar injustiças do passado.

Em suma, há uma inconciliável divergência teórica entre Nozicki e Rawls. Ainda que Rawls também seja um autor liberal, marcado pelo conceito do capitalismo (o que se verifica a partir da primazia a ele conferida ao princípio da liberdade) sua proposta de redistribuição dos bens econômicos e sociais é incompatível com a tese de Estado mínimo defendida por Nozicki, em que a interferência do Estado na propriedade legitimamente adquirida é eticamente inaceitável.

\section{AS CRÍTICAS DE ENRIQUE DUSSEL E O MOMENTO FORMAL DA ÉTICA}

Enrique Dussel, um dos maiores filósofos partidários da defesa da Filosofia da Libertação e pensamento latino-americano, possui várias críticas à teoria proposta por Rawls, que se diferem largamento dos demais críticos analisados anteriormente. Suas considerações dizem respeito, em especial, quanto à aplicabilidade da teoria rawlsiana mediante um caráter universal, fora da visão eurocentrista de mundo.

No início de sua análise já crítica o formalismo e artificialismo da teoria, na medida em que estaria negando o aspecto material da ética (DUSSEL, 2000, p. 176). Dussel concorda que há um descompasso entre o princípio original do utilitarismo em atingir a felicidade do maior número de pessoas, em razão do sistema capitalista, e a preocupação das consequências injustas pela distribuição de riqueza. Para ele, “é impossível (impossibilidade não lógica mas empírica) que a totalidade da população seja real e completamente feliz distributivamente dentro do atual sistema econômico" (DUSSEL, 2000, p. 113).

Ou seja, o utilitarismo poderia ser utilizado, ao contrário do propósito inicial, como 
argumento legítimo das instituições para satisfação dos interesses das maiorias políticas em detrimento das minorias.

Neste caso, a ideia de Rawls teria permitido avançar a discussão da ética, ao introduzir o tema das desigualdades, mas teria se mostrado incapaz de dar-lhe uma solução crítica. Afinal, uma sociedade ideal ocorreria se os membros da comunidade tivessem condições materiais adequadas, e não apenas condições formais de uma vida racional.

Dussel também critica a utilização do "véu da ignorância” por Rawls, ou seja, o que ele denomina "esquecimento fundante" do Estado. Isto porque o véu da ignorância seria um recurso hipotético e de impossível factibilidade, na medida em que as condições naturais e de nascimento são históricas e econômicas. Ou seja, se alguns indivíduos possuem maiores condições econômicas ao nascerem em determinada estrutura familiar, então o processo de acumulação do capital já teria se efetivado antes mesmo do nascimento.

Rawls pressupõe o momentâneo esquecimento da posição dos participantes da sociedade, no entanto, seria possível esquecer a linguagem? Dussel conclui que não, uma vez que não se poderiam fazer propostas que decorrem da relação comunicativa. Ocorre que cada um tem sua própria linguagem, o operário, o aristocrata, etc. E neste caso, ainda mais importante, quais seriam as pessoas que estipulariam o tipo de esquecimento proposto?

Rawls sustenta que a intenção da ideia de posição originária é estabelecer um procedimento imparcial de modo que quaisquer que sejam os princípios adotados estes necessariamente serão justos. Sobre esse ponto, Dussel fala que uma posição puramente formal não pode ensejar a decisão sobre princípios materiais. Nesse aspecto se verifica a crítica de Dussel ao formalismo neocontratualista rawlsiano.

Também em relação aos princípios fundamentais da justiça propostos por Rawls, Dussel afirma que se tratariam de meios encontrados pelo capitalismo para justificar as desigualdades, ou seja, pressuposto da teoria liberal. Isto porque os participantes da teoria proposta por Rawls seriam liberais norte-americanos que partiriam de noções vinculadas ao sistema capitalista.

No entanto, como explica Gargarella, a teoria de Rawls não foi imaginada para uma sociedade desigual, mas sim em uma hipótese em que predomina o sentimento de justiça "onde não existe nem uma extrema escassez nem uma abundância de bens; onde as pessoas são mais ou menos iguais entre si (quanto a suas capacidades físicas e mentais) e também vulneráveis às agressões dos demais [...]" (GARGARELLA, 2008, p. 20).

Dussel critica fortemente Rawls, inclusive chamando de "arrogância universalista" a 
suposição de que seria universal o que seria válido nos EUA (por exemplo, até mesmo para uma comunidade africana). Tratando especificamente dos princípios adotados por Rawls, Dussel irá dizer que o primeiro princípio que trata das iguais liberdades entre os membros da sociedade, resume a posição liberal de Rawls, uma vez que diz respeito a uma liberdade meramente formal.

Já o segundo princípio, calcado na igualdade, é propriamente material. No entanto, segundo Dussel, esse princípio ainda admitiria desigualdades e, mais grave, tais diferenças seriam tratadas como naturais para Rawls. De acordo com Dussel, Rawls tem dificuldade em compreender que um aspecto é a sorte de nascer em família mais ou menos afortunada, mas outro fator é que existam estruturas históricas e sociais (não naturais, portanto) que determinam essas desigualdades.

Se no primeiro princípio se fala de "igualdade", no segundo se admitem a priori (já que seriam fruto da "posição originária") "desigualdades (inequalities)". O leitor desprevenido se pergunta: Por que se admitem "igualdades" políticas ou formais e se propõem ao mesmo tempo "desigualdades" sociais e "econômicas (economic)"? Não se deveria formular, ao menos em princípio, uma igualdade social e econômica como ponto de partida? Nunca se dão razões para indicar o porquê desta contradição fundamental em todo o argumento de Rawls - em geral, os críticos de Rawls não tocam tampouco esta questão (o que indica que admitem essas desigualdades a priori). Mas é mais grave a questão, já que surgem argumentos para provar que essas desigualdades são "naturais". [...]. Rawls tem uma cegueira especial em compreender que a) um aspecto é a "sorte" de nascer em uma família mais ou menos afortunada (isto é pura casualidade), mas b) outro, que haja estruturas históricas (não naturais) e sociais em que nos cabe nascer, perfeitamente analisáveis, determináveis pela ciências sociais críticas: [...] (DUSSEL, 2000, p. 178-179).

Ainda que Rawls reconheça que tais desigualdades não são merecidas, fato é que, conforme Dussel, nunca as trata como injustiças. De toda sorte, Rawls mesmo defendendo o desmerecimento das desigualdades fala que elas não necessariamente precisariam ser eliminadas, pois seriam condições naturais de uma sociedade.

Além disso, como esta desigualdade faria parte dos princípios iniciais de uma sociedade, e como estes princípios constituem a estrutura básica da sociedade, as instituições criadas com base nessa estrutura reproduziriam também desigualdades.

Dussel ainda criticará a ideia de justiça como imparcialidade de Rawls. Para Rawls, tal ideia pressupõe a adesão aos princípios estabelecidos no contrato hipotético e a obediência às 
instituições dele decorrentes. Nesse sentido, tal ideia justificaria a obediência dos menos favorecidos às instituições intrinsecamente desiguais.

Assim, para Dussel o "estar pior colocado" em uma sociedade não seria um fato natural a ser aceito, como propõe Rawls, mas um dado histórico que merece justa reivindicação. Em outras palavras, Dussel desqualifica quase que inteiramente a teoria de Rawls por compreender que seria uma "mera falácia" do formalismo, com uma cega articulação com um capitalismo de centro.

\section{CONSIDERAÇÕES FINAIS}

A despeito das críticas à factibilidade de sua teoria, Rawls deve ser apreciado pela tentativa de rechaçar a ideia do conformismo com as falhas das instituições. Para ele, não seriam as aptidões naturais ou determinada posição da sociedade que seriam justas ou injustas, mas sim a maneira como as instituições trabalhariam com estes dois fatores.

Os princípios da justiça, deste modo, seriam as alternativas identificadas pelo autor para a construção deste pacto inicial que, se satisfeitos, não impediriam o crescimento pessoal dos indivíduos, mas demandariam a noção de compartilhamento das vantagens com os demais.

Rawls deve ser reconhecido pela ideia contrária ao utilitarismo e o risco da tirania da maioria sob a desculpa de uma participação da democracia representativa. Ou seja, sua ideia era de que as instituições não devem permitir o benefício de uns em detrimento de outros por questões políticas, ainda que a violação de bens fundamentais represente um bem coletivo maior. Uma injustiça só seria aceita como forma de evitar uma injustiça ainda maior.

Obviamente, a crítica de que sua teoria parte de uma concepção advinda do capitalismo faz total sentido, afinal de contas estamos a trabalhar com um filósofo liberal. Porém, a justiça distributiva, a partir da aplicação do princípio da diferença, seria uma forma identificada por Rawls para coibir os excessos advindos da riqueza ou da pobreza, e não somente do lado da acumulação como defendem alguns de seus críticos. 


\section{REFERÊNCIAS BIBLIOGRÁFICAS}

DUSSEL, Enrique. Ética da Libertação: Na idade da globalização e da exclusão. 2. ed. Petrópolis: Vozes, 2002.

GARGARELLA, Roberto. As Teorias da Justiça depois de Rawls: um breve manual de filosofia política. São Paulo: VMF. Martins Fontes, 2008.

MULHALL, Stephen; SWIFT, Adam. Liberals and Communitarians. 2. ed. Oxford: Blackwell Publishing, 1996.
NOZICK, Robert. Anarquia, Estado e Utopia. Rio de Janeiro: Jorge Zahar Editor, 2003.

RAWLS, John. Uma Teoria de Justiça. São Paulo: Martins Fontes, 2000.

SANDEL, Michael. Liberalism and the Limits of Justice. 2. ed. Cambridge: Cambridge University Press, 1998.

SANDEL. Michael J. Justiça: o que é fazer a coisa certa. $4^{\text {a }}$. ed. Rio de Janeiro: Civilização Brasileira, 2011.

DAS NEVES, B., SERENATO, M. W. Os Princípios de Justiça de Rawls e as Críticas à Teoria de Justiça. Complexitas - Rev. Fil. Tem. Belém, v. 3, n. 2, p. 66-84, jul./dec. 2018. Disponível em:< http://www.periodicos.ufpa.br/index.php/complexitas/article/view/6121>. Acesso em: 07 de julho de 2019. 